\title{
Canadian Society for Renaissance Studies Société canadienne d'études de la Renaissance
}

The Canadian Society for Renaissance Studies invites you to become a member of this unique bilingual Learned Society devoted to the development of Renaissance Studies in Canada and abroad.

Members receive our Newsletter, three times a year, can participate in our annual congress, and can subscribe to Renaissance and Reformation / Renaissance et Réforme and to ITER at a special rate. The Newsletter disseminates information about members' scholarship.

For information and membership form, please check our website (www.crrs.ca/ csrs-scer) or contact our treasurer Dr. Joseph Khoury (jkhoury@stfx.ca).

La Société canadienne d'études de la Renaissance vous invite à devenir membre de notre société bilingue qui se consacre au développement des études de la Renaissance au Canada et à l'étranger.

Nos adhérents reçoivent notre Bulletin, trois fois par an, sont invités à participer à notre congrès annuel, et peuvent souscrire à prix reduit à la revue Renaissance and Reformation / Renaissance et Réforme et à la base de données ITER. Le Bulletin de la SCÉR a pour mandat de diffuser les publications et les découvertes scientifiques des membres de notre société.

Prière de télécharger le bulletin d'adhésion à partir de notre site Internet (www. crrs.ca/csrs-scer) ou de communiquer avec notre trésorier, Monsieur Joseph Khoury (jkhoury@stfx.ca). 